\title{
Epithelial expression of FHL2 is negatively associated with metastasis-free and overall survival in colorectal cancer
}

\author{
L Verset $^{1}$, J Tommelein ${ }^{2}, X_{\text {Moles Lopez }}^{3,4}$, C Decaestecker $^{3,4}$, M Mareel $^{2}$, M Bracke $^{2}$, I Salmon ${ }^{1,4}$, \\ O De Wever ${ }^{2}$ and P Demetter ${ }^{*}, 1$
}

${ }^{1}$ Department of Pathology, Erasme University Hospital, Université Libre de Bruxelles, Route de Lennik 808,1070 Brussels, Belgium; ${ }^{2}$ Laboratory of Experimental Cancer Research, Department of Radiation Oncology and Experimental Cancer Research, Ghent University Hospital, Universiteit Gent, De Pintelaan 185, 9000 Ghent, Belgium; ${ }^{3}$ Laboratory of Image Synthesis and Analysis, Brussels School of Engineering/Ecole Polytechnique de Bruxelles, Université Libre de Bruxelles, Avenue F.D. Roosevelt 50,1050 Brussels, Belgium and ${ }^{4}$ DIAPATH, Center of Microscopy and Molecular Imaging (CMMI), Rue Adrienne Bolland 8, 6041 Gosselies, Belgium

Background: Four-and-a-half LIM domains protein 2 (FHL2) is a component of the focal adhesion structures and has been suggested to have a role in cancer progression. It has been shown to be overexpressed in the colorectal cancer (CRC).

Methods: Here, we examined a possible prognostic value of FHL2 in CRC. Immunohistochemistry for FHL2 was performed on 296 CRCs without distant metastases at the time of surgery. Staining in the epithelial compartment was quantitatively evaluated using image analysis, and results were related to clinical variables. Antibody specificity was tested using small-interfering RNA transfection in hTERT-immortalised myofibroblasts.

Results: Varying degrees of cytoplasmic FHL2 expression by neoplastic epithelial cells were detectable in all cases. Higher FHL2 expression in the epithelial compartment was an independent adverse prognostic factor. Multivariate Cox analysis shows that expression in the tumour invasion front $(P<0.001)$ as well as in the centre of the tumour $(P<0.001)$ was associated with metachronous metastases independently of the clinicopathological variables; expression in the tumour invasion front was also associated with overall survival independently of the clinicopathological variables $(P<0.01)$.

Conclusion: Higher FHL2 expression is involved in CRC progression and correlates with the development of metachronous metastases and overall survival, suggesting that FHL2 is an independent adverse prognostic indicator for CRC.

Metastatic colorectal cancer (CRC) is one of the leading causes of cancer death in Western countries (Siegel et al, 2012). Although the overall 5-year survival from CRC is $\sim 60 \%$ in population-based series, prognosis is well established to be strongly linked to stage at presentation. However, there is variation in the prognosis for patients with the same-stage disease; hence, it is highly desirable to have additional markers more strictly related to the individual behaviour of the CRC in order to better individualise therapy. Such markers may serve as the basis for clinical trials to further improve the survival of patients with CRC, as well as avoid the unnecessary use of adjuvant treatment.

Four-and-a-half LIM domains protein 2 (FHL2), also known as downregulated in rhabdomyosarcoma LIM protein, is the second member of a small family of five proteins with four-and-a-half LIM domains (Genini et al, 1997). This domain is a specialised double zinc-finger protein motif that has versatile cellular roles as regulators of gene expression, cyto-architecture, cell adhesion, cell motility, and signal transduction (Rétaux and Bachy, 2002; 
Kadrmas and Beckerle, 2004; Johannessen et al, 2006). The acronym LIM is derived from the names of three transcription factors, Lin-11, Isl-1, and Mec-3, in which such a domain was first identified (Johannessen et al, 2006).

Four-and-a-half LIM domains protein 2 is expressed in many normal human tissues such as the heart, ovary, kidney, prostate, testis, small intestine, and colon (Genini et al, 1997; Chan et al, 1998; Scholl et al, 2000). The protein is intriguing because it can function as either an activator or repressor of target proteins in a cell type-dependent fashion. It functions also as a coactivator of many transcription factors, such as $\beta$-catenin, activator protein-1, CRE-binding protein and extracellular signal-regulated kinase 2 (Morlon and Sassone-Corsi, 2003; Wei et al, 2003; Johannessen et al, 2006); and as a corepressor of the promyelocytic leukaemia zinc-finger protein in muscle cells (McLoughlin et al, 2002).

Four-and-a-half LIM domains protein 2 has been identified as an oncoprotein in several types of cancer. The mRNA level of FHL2 is elevated in both low- and high-grade glioma, and overexpression of FHL2 stimulates the proliferation, anchorageindependent growth, and migration of human glioblastoma cells (Li et al, 2008). Nuclear localisation of FHL2 is associated with recurrence in prostate cancer (Kahl et al, 2006). Low FHL2 expression is related to better survival in patients with breast cancer (Gabriel et al, 2006). Four-and-a-half LIM domains protein 2 is highly expressed in human colon cancer, and cell line experiments showed that FHL2 is critical for migration and invasion (Zhang et al, 2010). Moreover, suppression of FHL2 in colon cancer cell lines induces cell differentiation and inhibits tumorigenesis (Wang et al, 2007).

In the present study, we aimed to investigate a possible prognostic role of FHL2 expression in a large series of CRC cases, without evidence of distant metastasis at the time of presentation; development of metastases and mortality are the outcome parameters. We thereby focus on expression of FHL2 in neoplastic epithelial cells.

\section{MATERIALS AND METHODS}

Patients. We retrospectively analysed tumour samples from consecutive patients who underwent surgical resection of a primary CRC, without evidence of distant metastasis at the time of surgery. All patients underwent surgical resection at the Erasme University Hospital (Brussels, Belgium) between May 1990 and December 2000. Sex, age and pTNM status were retrieved from medical reports. Follow-up was available until August 2009. The study was approved by the local ethics committee.

Basic patient demographical data are summarised in Table 1.

Tissue microarray construction. Tissue microarray (TMA) blocks were constructed as described previously (Decaestecker et al, 2009), with a manual microarrayer (Beecher Instruments, Sun Prairie, WI, USA) to include twelve cores $(600-\mu \mathrm{m}$ diameter) from each CRC case. Six cores were obtained from the central part of the tumour and six cores from the invasion front.

Immunohistochemistry for mismatch repair proteins and its evaluation. Standard immunohistochemistry was applied to $5-\mu \mathrm{m}$ thick sections to display MLH1, MSH2, MSH6 and PMS2 expression, using antibodies against MLH1 (Menarini, Zaventem, Belgium; clone ES05, dilution $1: 100$ ), MSH2 (Menarini; clone 25D12, dilution $1: 200$ ), MSH6 (Menarini; clone PU29, dilution $1: 400$ ) and PMS2 (Menarini; clone M0R4G, dilution 1/100), and was performed on the BOND-MAX (Leica, Wetzlar, Germany). Briefly, the immunohistochemical expression was visualised using the Bond Polymer Refine Detection kit (Menarini; kit DS9800). The sections were counterstained with haematoxylin.

\begin{tabular}{|c|c|c|c|}
\hline $\begin{array}{l}\text { Patient } \\
\text { characteristics }\end{array}$ & & $\begin{array}{l}\text { Tumoural } \\
\text { centre }\end{array}$ & $\begin{array}{c}\text { Tumoural } \\
\text { front }\end{array}$ \\
\hline$n$ & 296 & 249 & 167 \\
\hline Sex ratio (female:male) & $0.82(133: 163)$ & $0.81(112: 137)$ & $0.94(81: 86)$ \\
\hline Mean age (min-max) & 68 (27-92) & 68 (27-92) & $68(35-92)$ \\
\hline \multicolumn{4}{|l|}{ TNM status } \\
\hline T1 & $14(4.7 \%)$ & $11(4.4 \%)$ & $8(4.8 \%)$ \\
\hline $\mathrm{T} 2$ & 53 (18\%) & 47 (18.9\%) & 32 (19.2\%) \\
\hline T3 & $212(71.6 \%)$ & 179 (71.9\%) & $119(71.2 \%)$ \\
\hline T4 & $17(5.7 \%)$ & $12(4.8 \%)$ & $8(4.8 \%)$ \\
\hline NO & $173(58.4 \%)$ & 145 (58.2\%) & $96(57.5 \%)$ \\
\hline N1 & 89 (30.1\%) & 77 (31\%) & 51 (30.5\%) \\
\hline N2 & $34(11.5 \%)$ & 27 (10.8\%) & $20(12 \%)$ \\
\hline $\begin{array}{l}\text { Intact/defective MMR } \\
\text { protein expression }\end{array}$ & $261 / 20^{a}$ & $230 / 14^{b}$ & $152 / 10^{b}$ \\
\hline \multicolumn{4}{|c|}{ 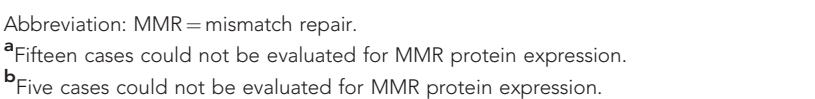 } \\
\hline
\end{tabular}

Mismatch repair (MMR) protein expression was divided into 'intact' and 'deficient' groups. Intact MMR protein expression was defined by nuclear expression of MLH1, MSH2, MSH6 and PMS2 in neoplastic epithelial cells (Resnick et al, 2010). If stromal cells were negative for at least one of these markers, the case was considered non-evaluable for MMR protein expression by lack of positive internal control.

Immunohistochemistry for FHL2 and its evaluation. Standard immunohistochemistry was applied to $5-\mu \mathrm{m}$ thick sections to display FHL2 expression, using a specific antibody provided by Abcam (Cambridge, UK; ab66399, dilution 1:200) and was performed on the BOND-MAX. Briefly, the immunohistochemical expression was visualised using the Bond Polymer Refine Detection kit. The sections were counterstained with haematoxylin.

We used the NanoZoomer 2.0-HT slide scanner (Hamamatsu, Louvain-La-Neuve, Belgium) for TMA core image acquisition and the NDP viewer software (Hamamatsu) to visually assess slides and image quality. Only the cores satisfying all the control steps were considered for staining evaluation as follows. In each core, the neoplastic epithelial cells were surrounded by a pathologist (LV) to study FHL2 expression specifically in them. A quantitative analysis was then performed using the Visiomorph software package (Visiopharm, Hoersholm, Denmark) to determine the labelling index (LI), which is the percentage of the immunostained-tissue area within the epithelial compartment. This evaluation was performed for each TMA core and pooled per patient by distinguishing central tumour part from invasion front, as detailed elsewhere (Decaestecker et al, 2009). To ensure representativeness, only reference regions for which at least two cores could be evaluated were included for further analysis.

Immunohistochemistry for E-cadherin and $\beta$-catenin and its evaluation. Immunohistochemical stainings for FHL2 and for the EMT-markers E-cadherin and $\beta$-catenin were performed on consecutive $5-\mu \mathrm{m}$ thick sections of 10 randomly chosen CRC resection specimens. For FHL2, staining was performed as described above. For E-cadherin and $\beta$-catenin, we used antibodies provided by Dako (Glostrup, Denmark; NCH-38, dilution 1:100; $\beta$-catenin 1, dilution $1: 300)$. Stainings were performed on the BOND-MAX. Briefly, the immunohistochemical expression was visualised using the Bond Polymer Refine Detection kit for E-cadherin, and the Bond Intense R Detection kit (Menarini; kit 
DS9263) for $\beta$-catenin. The sections were counterstained with haematoxylin. The consecutive slides were evaluated by two pathologists (LV and PDM) using an Olympus BX50 microscope (Olympus Belgium, Aartselaar, Belgium).

Cell cultures and transfections. hTERT-immortalised human colon tumour-derived myofibroblasts (De Wever et al, 2004) were maintained in DMEM (Invitrogen, Gent, Belgium) supplemented with $10 \%$ foetal bovine serum and antibiotics. Small-interfering RNA (siRNA)-targeting FHL2 (5'-AAG GTA ATG ACC AGT TGT TAT- $3^{\prime}$ ) and scrambled RNAi-negative control (Qiagen, Venlo, The Netherlands) were transfected by electroporation (Cell line nucleofector kit V, Lonza, Basel, Switzerland).

Immunocytochemistry and western blot on cultured cells. For immunocytochemistry, pellets of hTERT-immortalised myofibroblasts were fixed in $4 \%$ buffered formol for $12 \mathrm{~h}$, followed by a wash with PBS and transfer to $70 \%$ ethanol, and then embedded in paraffin, sectioned, and stained with the anti-FHL2 antibody. For counterstaining, haematoxylin was used.

For western blot analysis, hTERT-immortalised myofibroblasts $\left(1-10 \times 10^{6}\right)$ were harvested in Laemmli lysis buffer $(0.125 \mathrm{M}$ Tris$\mathrm{HCl}(\mathrm{pH}=6.8), 10 \%$ glycerol, $2.3 \% \mathrm{SDS})$. Cell lysates $(25 \mu \mathrm{g})$ were suspended in $10 \mu \mathrm{l}$ reducing sample buffer $(1 \mathrm{M}$ Tris-HCl $(\mathrm{pH}=6.8), \quad 30 \%$ glycerol, $6 \%$ SDS, 3\% $\beta$-mercaptoethanol, $0.005 \%$ bromophenol blue) and boiled for $5 \mathrm{~min}$ at $95^{\circ} \mathrm{C}$. Samples were subjected to SDS-PAGE gels, transferred to PVDF membranes, blocked in 5\% non-fat milk in PBS with $0.5 \%$ Tween-20 and immunostained. The anti-FHL2 antibody as well as a mouse monoclonal antitubulin (Sigma-Aldrich, St. Louis, MO, USA) were used.

Statistical analysis. Multivariate survival analyses were performed using the standard Cox regression. We first analysed the set of clinicopathological variables presented in Table 1 and then selected those showing a contribution characterised by a $P$-value $<0.05$. We then added the FHL2 LI to the 'clinical' model to test its potential prognostic contribution with development of metastases and mortality as outcome parameters; time to development of metastases was calculated as the time between surgical intervention and detection of metastases on imaging grounds, and the time to mortality as time between surgery and death, as registered at the community level. This prognostic impact was also illustrated by means of the standard Kaplan-Meier analysis and the WilcoxonGehan test.
Four-and-a-half LIM domains protein 2 expression in the tumour invasion front and in the tumour centre was considered separately.

For each statistical analysis, the cases presenting missing value(s) in the concerned variable(s) were omitted.

\section{RESULTS}

Study population. Tumour samples from 296 cases could be included; clinical and histopathological data are presented in Table 1. Final analysis for FHL2 expression could be performed for the tumour invasion front of 167 patients, and for the tumour centre of 249 patients.

FHL2 expression in CRCs. We studied the expression of FHL2 using a validated anti-FHL2 antibody (Figure 1) and observed varying degrees of cytoplasmic FHL2 expression by neoplastic epithelial cells in all cases (Figure 2) in the invasion front as well as in the centre of the tumour. This cytoplasmic expression was often more prominent at the cellular periphery. Nuclear FHL2 expression was not observed.

In addition, cytoplasmic FHL2 expression could be detected in elongated, mesenchymal-appearing cells of the tumour stroma.

Prognostic evaluation of FHL2 expression. Using multivariate survival analyses, we first identified the clinicopathological variables with impact on prognosis in the complete case series of 296 CRC patients. The results showed that age and $\mathrm{N}$ stage are independent negative prognostic factors for overall survival, and female gender and $\mathrm{N}$ stage for the development of metachronous metastases (data not shown). Taking these factors into account, we identified higher FHL2 expression at the tumour invasion front as well as at the tumour centre being an independent negative prognostic factor (both with $P<0.001$, see Table 2), associated with the development of metachronous metastases. Moreover, FHL2 expression in the tumour invasion front was also associated with overall survival independently of the clinicopathological variables $(P<0.05$, see Table 2$)$.

By analysing the distribution of the FHL2 LI values in order to stratify the patients in relation to their metastasis-free survival, we found that $<20 \%$ of the patients with a LI $\leqslant 40 \%$ in the tumour invasion front or in the tumour centre had a short metastasis-free survival (in contrast to patients with $\mathrm{LI}>40 \%$, see Supplementary Figure 1). The Kaplan-Meier curves shown in Figure $3 \mathrm{~B}$ and $\mathrm{C}$

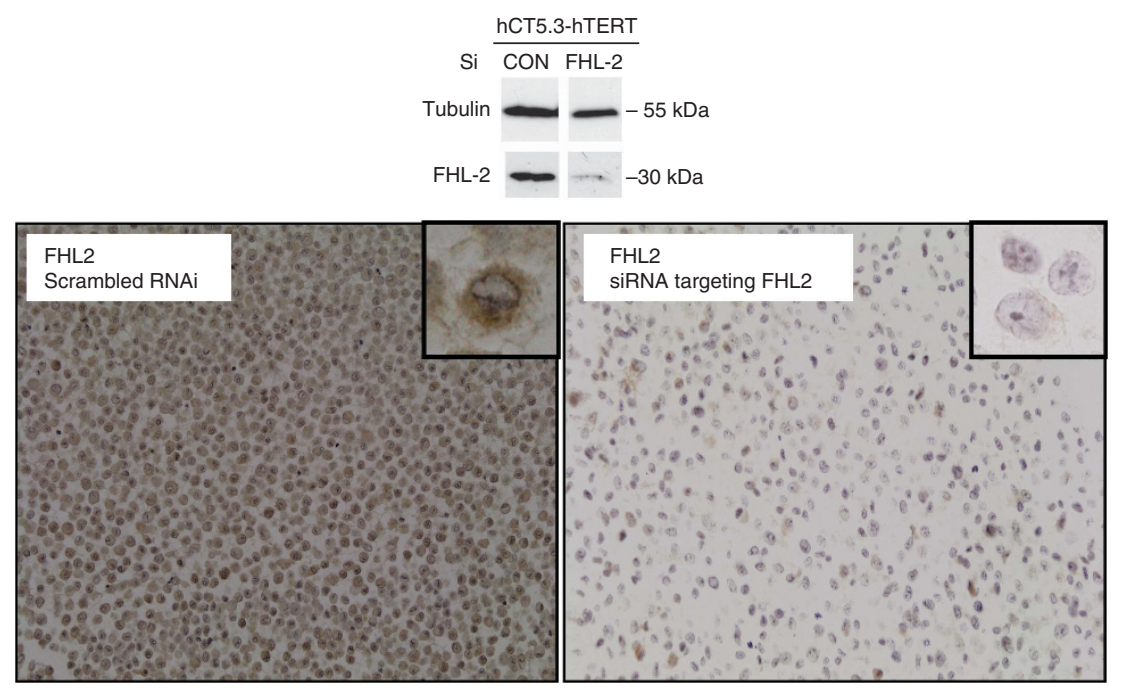

Figure 1. Western blot analysis (upper) and imunocytochemistry (lower) of FHL2 protein expression in hTERT-immortalised myofibroblasts after transfection with siRNA-targeting FHL2 and scrambled RNAi-negative control, confirming thereby the specificity of the FHL2 antibody used in this work (magnification $\times 200$ ). Inserts show details of FHL2 expression. 


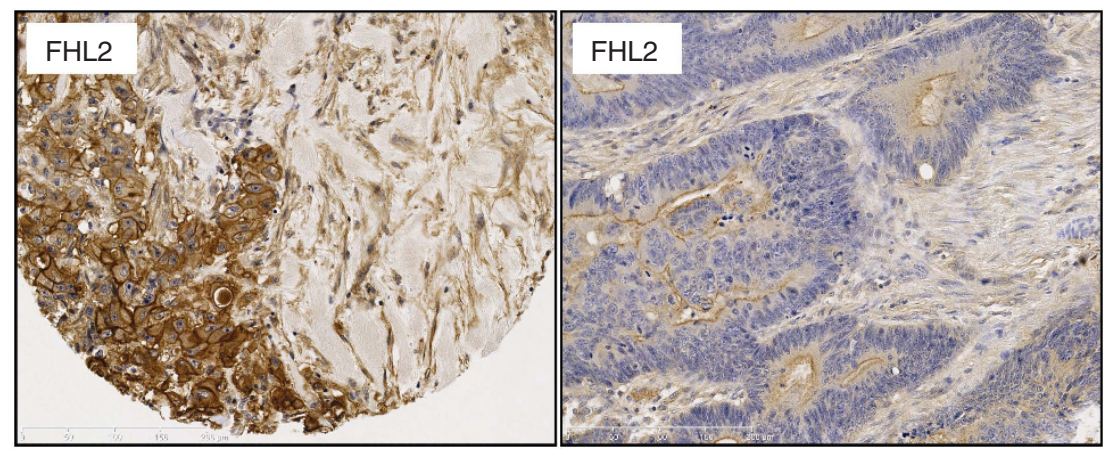

Figure 2. Four-and-a-half LIM domains protein 2 expression in neoplastic epithelial cells and fibroblasts. Diffuse (left) and focal (right) positivity in neoplastic epithelium (magnification $\times 200$ ).

Table 2. Multivariate analysis of overall survival and metastasis-free survival

\begin{tabular}{|c|c|c|c|c|c|c|c|c|c|}
\hline \multicolumn{5}{|c|}{ Tumoural centre $(n=249)$} & \multicolumn{5}{|c|}{ Tumoural front $(n=167)$} \\
\hline $\begin{array}{l}\text { Model } \\
P \text {-value }\end{array}$ & $\begin{array}{c}\text { Prognostic } \\
\text { factors }\end{array}$ & HR & $95 \% \mathrm{Cl}$ & $\boldsymbol{P}$-value & $\begin{array}{l}\text { Model } \\
\text { P-value }\end{array}$ & $\begin{array}{c}\text { Prognostic } \\
\text { factors }\end{array}$ & HR & $95 \% \mathrm{Cl}$ & $P$-value \\
\hline \multicolumn{10}{|c|}{ Overall survival } \\
\hline 0.00000 & $\begin{array}{c}\text { Age } \\
N \\
\text { FHL2 LI }\end{array}$ & $\begin{array}{l}1.03 \\
1.91 \\
1.87\end{array}$ & $\begin{array}{l}1.01-1.05 \\
1.52-2.40 \\
0.71-4.96\end{array}$ & $\begin{array}{l}0.00041 \\
0.00000 \\
0.20612\end{array}$ & 0.00000 & $\begin{array}{c}\text { Age } \\
N \\
\text { FHL2 LI }\end{array}$ & $\begin{array}{l}1.05 \\
2.54 \\
3.38\end{array}$ & $\begin{array}{l}1.02-1.07 \\
1.89-3.40 \\
1.24-9.21\end{array}$ & $\begin{array}{l}0.00004 \\
0.00000 \\
0.01747\end{array}$ \\
\hline \multicolumn{10}{|c|}{ Metastasis-free survival } \\
\hline 0.00000 & $\begin{array}{c}\text { Male } \\
\text { N } \\
\text { FHL2 LI }\end{array}$ & $\begin{array}{r}0.62 \\
2.69 \\
12.25\end{array}$ & $\begin{array}{l}0.39-0.99 \\
1.99-3.65 \\
3.29-45.61\end{array}$ & $\begin{array}{l}0.04326 \\
0.00000 \\
0.00019\end{array}$ & 0.00000 & $\begin{array}{c}\text { Male } \\
\text { N } \\
\text { FHL2 LI }\end{array}$ & $\begin{array}{r}0.40 \\
3.26 \\
11.51\end{array}$ & $\begin{array}{l}0.22-0.73 \\
2.28-4.67 \\
3.23-41.05\end{array}$ & $\begin{array}{l}0.00285 \\
0.00000 \\
0.00016\end{array}$ \\
\hline
\end{tabular}

Abbreviations: $\mathrm{Cl}=$ confidence interval; $\mathrm{FHL} 2=$ four-and-a-half $\mathrm{LIM}$ domains protein $2 ; \mathrm{HR}=$ hazard ratio; $\mathrm{LI}=$ labelling index. Cox proportional-hazards regression model: model $P$-value indicates the overall level of significance of the multivariate model; the individual $P$-values represent the levels of significance of the independent contributions of each variable (where $N$ takes the values: 0,1 and 2).

confirm the significant prognostic value of this FHL2 threshold for the invasion front and the centre, respectively, (both with $P<0.001)$. Figure $3 \mathrm{~A}$ also demonstrates the significant prognostic value of this threshold for the invasion front with regard to overall survival $(P<0.01)$. A similar result was obtained for FHL2 expression in the tumour centre (data not shown); however, this expression is not an independent prognostic factor (see Table 2).

Expression of FHL2 in relation to E-cadherin and $\beta$-catenin. In a pilot experiment including 10 cases, foci of intense FHL2 expression with concomitant reduced E-cadherin expression and appearance of nuclear expression of $\beta$-catenin could be demonstrated in consecutive sections. These foci were found in EMT areas, characterised by poor differentiation of the cancer, and presence of small clusters of cancer cells and isolated cancer cells in the extracellular matrix-rich peritumoural stroma (Figure 4).

\section{DISCUSSION}

In this study, we demonstrated that higher FHL2 expression in malignant epithelial cells correlates with progressive disease in patients with CRC, suggesting that FHL2 is an independent and reliable prognostic indicator for the development of metachronous metastases and for overall survival in this type of cancer. This is consistent with the finding that FHL2 promotes invasive potential in colon cancer (Zhang et al, 2010).
During cancer progression, advanced tumour cells frequently exhibit a conspicuous downregulation of epithelial markers and a loss of intercellular junctions, resulting in a loss of epithelial polarity and reduced intercellular adhesion. These alterations are often accompanied by nuclear accumulation of $\beta$-catenin, increased cell motility and expression of mesenchymal-specific proteins such as vimentin (Vermeulen et al, 1995; Huber et al, 2005; Turley et al, 2008; Iwatsuki et al, 2010). This process called EMT can therefore promote invasion and metastasis (Bates and Mercurio, 2005; Huber et al, 2005; Turley et al, 2008).

One of the decreased epithelial markers during EMT is E-cadherin (De Wever et al, 2008). Four-and-a-half LIM domains protein 2 negatively regulates the transcription of E-cadherin through interaction with Snail 1 (Zhang et al, 2010, 2011). Moreover, FHL2 stimulates vimentin and matrix metalloproteinase-9 expressions (Zhang et al, 2010). Other arguments for a role of FHL2 in EMT come from a gain-of-function experiment in which the overexpression of FHL2 in a fish pre-osteoblastic cell line promoted cell dedifferentiation and altered gene expression profile in agreement with an EMT-like phenotype (Rafael et al, 2012). In contrast to others (Zhang et al, 2010), we did not detect nuclear FHL2 expression in CRC, using a well-defined and validated antibody; therefore, we suggest that FHL2 interacts via cytoplasmic/cell periphery protein interactions, rather than via direct transcriptional activation or repression, in the progression of CRC, including EMT. 

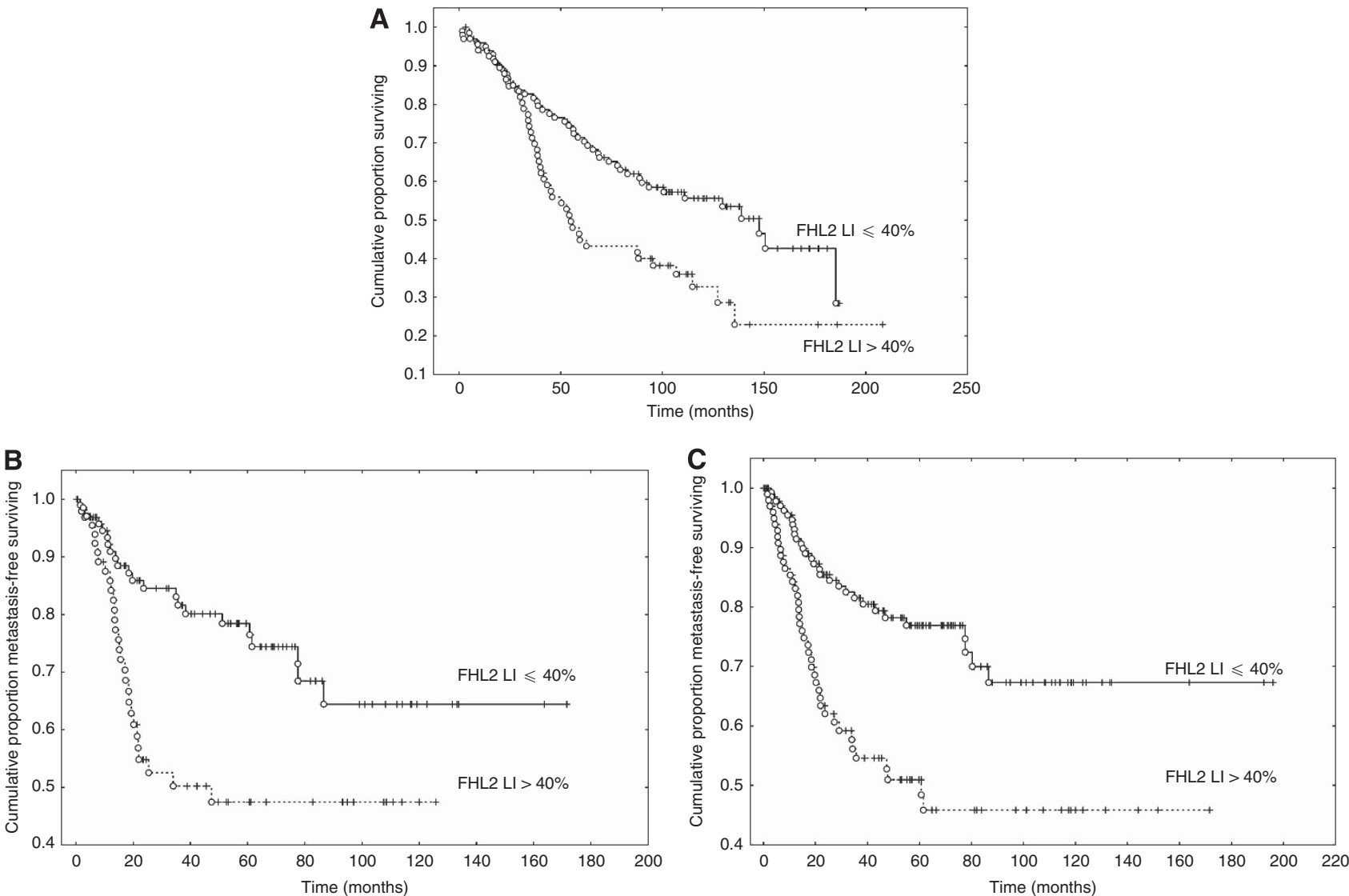

Figure 3. Prognostic value of FHL2 expression. (A) Overall survival curve of patients dichotomised on the basis of the FHL2 LI evaluated in tumour invasion front $(P<0.01)$. ( $\mathbf{B}$ and $\mathbf{C})$ : Metastasis-free survival curves of patients dichotomised on the basis of the $\mathrm{FHL} 2 \mathrm{LI}$ evaluated in (B) tumour invasion front $(P<0.001)$ and $(C)$ tumour centre $(P<0.001)$. Complete and censured data are shown by dots and crosses, respectively.

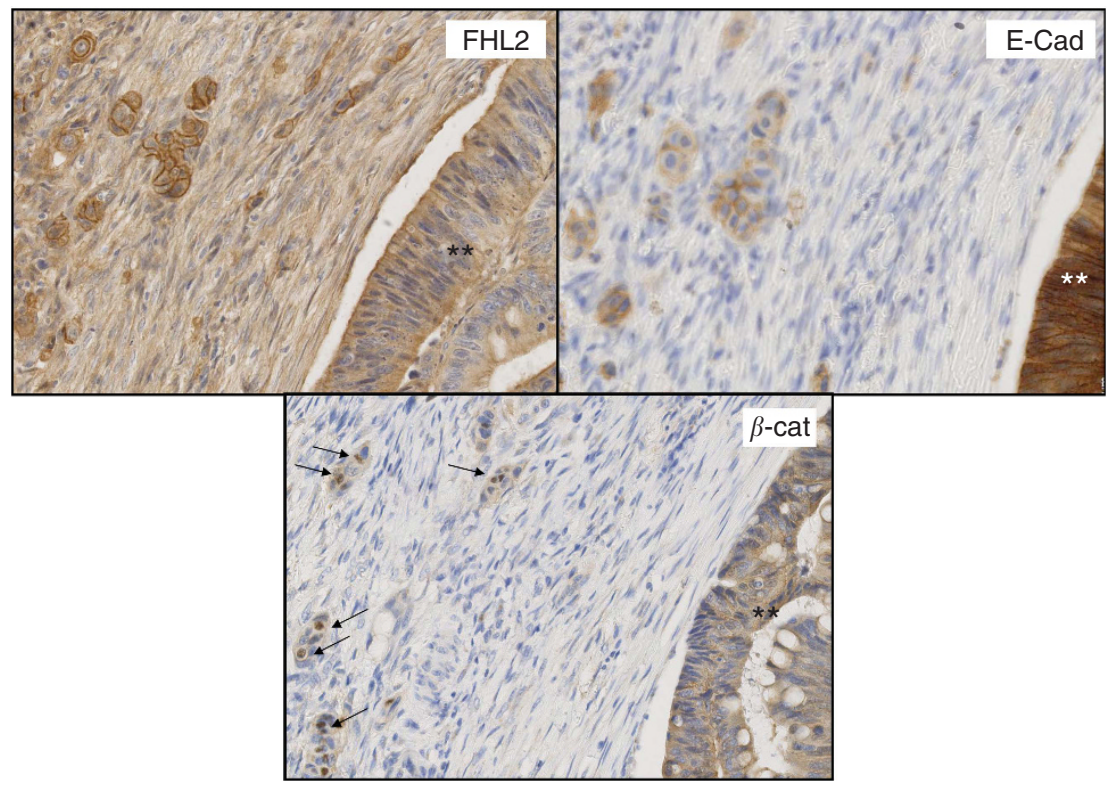

Figure 4. Consecutive sections with foci of (upper left) intense FHL2 expression with concomitant (upper right) reduced E-cadherin expression and (lower) appearance of nuclear expression of $\beta$-catenin (arrows) in areas of EMT. Note the lower FHL2 expression as well as the stronger E-cadherin expression and the absence of nuclear $\beta$-catenin expression in adjacent well-differentiated tumour glands (**; magnification $\times 400)$.

Multiple functions have been ascribed to FHL2, and it is puzzling how a protein that consists of LIM domains only and that lacks any obvious enzymatic activity can exert such a functional diversity. Four-and-a-half LIM domains protein 2 can interact with $>50$ different proteins that belong to different functional classes, including receptors (Kurakula et al, 2011; Matulis and Mayo, 2012), structural proteins (Lange et al, 2002; Coghill et al, 2003), transcription factors and cofactors (Samson et al, 2004; 
Han et al, 2009; Hubbi et al, 2012), splicing factors (Dye and Patton, 2001; Ng et al, 2002), DNA replication and repair enzymes (Chan et al, 2000; Yan et al, 2003), and enzymes (Jiang et al, 2002; Lange et al, 2002; Wang et al, 2012). The biological importance of many of these protein-protein interactions has not been determined, but such information will contribute to further clarifying the roles of FHL2 in colorectal and other cancers. Cellspecific expression and cell-specific subcellular distribution of FHL2, as well as the available concentrations of the interacting partners may partially favour certain interactions. The abundance of extracellular matrix in EMT areas do suggest that following integrin engagement, FHL2 localises to focal adhesions.

Our study does not allow identification of molecular mechanisms behind FHL2 upregulation in CRC, which may be the result of nonspecific deregulation of gene expression as a characteristic of a more aggressive tumoural phenotype. It is, however, noteworthy that computer analysis of the FHL2 promoter revealed a plethora of putative transcription factor-binding sites (Heinemeyer et al, 1998), suggesting a complex transcriptional regulation.

In our series, fibroblasts within carcinoma tissue also showed FHL2 expression, thereby confirming results from a study specifically investigating FHL2 in peritumoural fibroblasts (Gullotti et al, 2011). In that study, FHL2 expression in peritumoural fibroblasts correlated with lymphatic metastasis in sporadic CRC but not in CRC with mutation in MMR genes; in the present work, we did not study any possible link between MMR protein and FHL2 expression, given the low number of cases in which defective MMR protein expression had been demonstrated.

Our results also suggest that FHL2 blockade could be an effective therapeutic approach in selected CRC patients. Four-anda-half LIM domains protein 2 is a LIM protein that mediates protein-protein interactions and is found in focal adhesions where it functions as an interacting hub to bind focal adhesion kinase (FAK) and others, possible substrates of FAK (Gabriel et al, 2004). A crucial event in integrin-mediated signal transduction is the phosphorylation of proteins on tyrosine residues, mainly mediated by the FAK. Several companies have designed specific inhibitors of FAK activity (e.g. GSK2256098); these are currently in clinical trials and have the potential to inhibit downstream events of FHL2-mediated signalling (Schultze and Fiedler, 2011). Other approaches are pharmacological targeting of downstream signalling initiated by FHL2; examples are Wnt signalling (Brun et al, 2013) and TGF- $\beta$ signalling (Xia et al, 2013). Moreover, in vitro experiments have shown that blocking FHL2 expression by siRNA could inhibit the growth and proliferation of human CRC cells (Ji et al, 2009); in that study, chitosan-based siRNA nanoparticles were a very efficient delivery system for siRNA in vivo. The efficacy in human CRC remains, however, to be clarified.

In conclusion, we showed using a validated antibody that CRC patients with high FHL2 protein levels in neoplastic epithelium have a significantly higher probability of developing metachronous metastases and have a shorter overall survival, indicating a prognostic and contributing role of FHL2 in this tumour. Although conducted on a large population, our study is retrospective and monocentric; thus, our data need to be confirmed by prospective independent series. We suggest that targeting of FHL2 may have a promising role in the management of $\mathrm{CRC}$; further research unravelling the molecular mechanisms behind our observation is, however, warranted.

\section{ACKNOWLEDGEMENTS}

We thank Audrey Verrellen for excellent technical assistance. This work was supported by doctoral grants from the Fonds Erasme (LV) and the Télévie program of the 'Fonds National de la
Recherche Scientifique' (XML), by a postdoctoral grant from Fund for Scientific Research-Flanders (ODW), by the 'Foundation Yvonne Boël' (Brussels, Belgium) and by the Vlaamse Liga tegen Kanker. $\mathrm{CD}$ is a Senior Research Associate with the 'Fonds National de la Recherche Scientifique', Brussels, Belgium. The CMMI is supported by the European Regional Development Fund and the Walloon Region.

\section{REFERENCES}

Bates RC, Mercurio AM (2005) The epithelial-mesenchymal transition (EMT) and colorectal cancer progression. Cancer Biol Ther 4: 365-370.

Brun J, Dieudonné FX, Marty C, Müller J, Schüle R, Patino-Garcia A, Lecanda F, Fromigué O, Marie PJ (2013) FHL2 silencing reduces Wnt signaling and osteosarcoma tumorigenesis in vitro and in vivo. PloS One 8: e55034.

Chan KK, Tsui SK, Lee SM, Luk SC, Liew CC, Fung KP, Waye MM, Lee CY (1998) Molecular cloning and characterization of FHL2, a novel LIM domain protein preferentially expressed in human heart. Gene 210: 345-350.

Chan KK, Tsui SK, Ngai SM, Lee SM, Kotaka M, Waye MM, Lee CY, Fung KP (2000) Protein-protein interaction of FHL2, a LIM domain protein preferentially expressed in human heart, with hCDC47. J Cell Biochem 76: 499-508.

Coghill ID, Brown S, Cottle DL, McGrath MJ, Robinson PA, Nandurkar HH, Dyson JM, Mitchell CA (2003) FHL3 is an actin-binding protein that regulates alpha-actinin-mediated actin bundling: FHL3 localizes to actin stress fibers and enhances cell spreading and stress fiber disassembly. J Biol Chem 278: 24139-24152.

De Wever O, Nguyen QD, Van Hoorde L, Bracke M, Bruyneel E, Gespach C, Mareel M (2004) Tenascin-C and SF/HGF produced by myofibroblasts in vitro provide convergent pro-invasive signals to human colon cancer cells through RhoA and Rac. FASEB J 18: 1016-1018.

De Wever O, Pauwels P, De Craene B, Sabbah M, Emami S, Redeuilh G, Gespach C, Bracke M, Berx G (2008) Molecular and pathological signatures of epithelial-mesenchymal transitions at the cancer invasion front. Histochem Cell Biol 130: 481-494.

Decaestecker C, Lopez XM, D'Haene N, Roland I, Guendouz S, Duponchelle C, Berton A, Debeir O, Salmon I (2009) Requirements for the valid quantification of immunostains on tissue microarray materials using image analysis. Proteomics 9: 4478-4494.

Dye BT, Patton JG (2001) An RNA recognition motif (RRM) is required for the localization of PTB-associated splicing factor (PSF) to subnuclear speckles. Exp Cell Res 263: 131-144.

Gabriel B, Fischer DC, Orlowska-Volk M, zur Hausen A, Schüle R, Müller JM, Hasenburg A (2006) Expression of the transcriptional coregulator FHL2 in human breast cancer: a clinicopathologic study. J Soc Gynecol Investig 13: 69-75.

Gabriel B, Mildenberger S, Weisser CW, Metzger E, Gitsch G, Schüle R, Müller JM (2004) Focal adhesion kinase interacts with the transcriptional coactivator FHL2 and both are overexpressed in epithelial ovarian cancer. Anticancer Res 24: 921-927.

Genini M, Schwalbe P, Scholl FA, Remppis A, Mattei MG, Schäfer BW (1997) Subtractive cloning and characterization of DRAL, a novel LIM-domain protein down-regulated in rhabdomyosarcoma. DNA Cell Biol 16: 433-442.

Gullotti L, Czerwitzki J, Kirfel J, Propping P, Rahner N, Steinke V, Kahl P, Engel C, Schüle R, Buettner R, Friedrichs N (2011) FHL2 expression in peritumoural fibroblasts correlates with lymphatic metastasis in sporadic but not in HNPCC-associated colon cancer. Lab Invest 91: 1695-1705.

Han W, Wu Z, Zhao Y, Meng Y, Si Y, Yang J, Fu X, Yu L (2009) FHL2 interacts with and acts as a functional repressor of Id2 in human neuroblastoma cells. Nucleic Acids Res 37: 3996-4009.

Heinemeyer T, Wingender E, Reuter I, Hermjakob H, Kel AE, Kel OV, Ignatieva EV, Ananko EA, Podkolodnaya OA, Kolpakov FA, Podkolodny NL, Kolchanov NA (1998) Databases on transcriptional regulation: TRANSFAC, TRRD and COMPEL. Nucleic Acids Res 26: 364-370.

Hubbi ME, Gilkes DM, Baek JH, Semenza GL (2012) Four-and-a-half LIM domain proteins inhibit transactivation by hypoxia-inducible factor 1 . J Biol Chem 287: 6139-6149. 
Huber MA, Kraut N, Beug H (2005) Molecular requirements for epithelialmesenchymal transition during tumor progression. Curr Opin Cell Biol 17: 548-558.

Iwatsuki M, Mimori K, Yokobori T, Ishi H, Beppu T, Nakamori S, Baba H, Mori M (2010) Epithelial-mesenchymal transition in cancer development and its clinical significance. Cancer Sci 101: 293-299.

Ji AM, Su D, Che O, Li WS, Sun L, Zhang ZY, Yang B, Xu F (2009) Functional gene silencing mediated by chitosan/siRNA nanocomplexes. Nanotechnology 20: 405103.

Jiang LQ, Wen SJ, Wang HY, Chen LY (2002) Screening the proteins that interact with calpain in a human heart cDNA library using a yeast twohybrid system. Hypertens Res 25: 647-652.

Johannessen M, Møller S, Hansen T, Moens U, Van Ghelue M (2006) The multifunctional roles of the four-and-a-half-LIM only protein FHL2. Cell Mol Life Sci 63: 268-284.

Kadrmas JL, Beckerle MC (2004) The LIM domain: from the cytoskeleton to the nucleus. Nat Rev Mol Cell Biol 5: 920-931.

Kahl P, Gullotti L, Heukamp LC, Wolf S, Friedrichs N, Vorreuther R, Solleder G, Bastian PJ, Ellinger J, Metzger E, Schüle R, Buettner R (2006) Androgen receptor coactivators lysine-specific histone demethylase 1 and four and a half LIM domain protein 2 predict risk of prostate cancer recurrence. Cancer Res 66: 11341-11347.

Kurakula K, van der Wal E, Geerts D, van Tiel CM, de Vries CJ (2011) FHL2 protein is a novel co-repressor of nuclear receptor Nur77. J Biol Chem 30: $44336-44343$.

Lange S, Auerbach D, McLoughlin P, Perriard E, Schäfer BW, Perriard JC, Ehler E (2002) Subcellular targeting of metabolic enzymes to titin in heart muscle may be mediated by DRAL/FHL-2. J Cell Sci 115: 4925-4936.

Li M, Wang J, Ng SS, Chan CY, Chen AC, Xia HP, Yew DT, Wong BC, Chen Z, Kung HF, Lin MC (2008) The four-and-a-half-LIM protein 2 (FHL2) is overexpressed in gliomas and associated with oncogenic activities. Glia 56: 1328-1338.

Matulis CK, Mayo KE (2012) The LIM Domain Protein FHL2 Interacts with the NR5A Family of Nuclear Receptors and CREB to Activate the Inhibin- $\alpha$ Subunit Gene in Ovarian Granulosa Cells. Mol Endocrinol 26: 1278-1290.

McLoughlin P, Ehler E, Carlile G, Licht JD, Schäfer BW (2002) The LIM-only protein DRAL/FHL2 interacts with and is a corepressor for the promyelocytic leukemia zinc finger protein. J Biol Chem 277: 37045-37053.

Morlon A, Sassone-Corsi P (2003) The LIM-only protein FHL2 is a seruminducible transcriptional coactivator of AP-1. Proc Natl Acad Sci USA 100: 3977-3982.

Ng EK, Chan KK, Wong CH, Tsui SK, Ngai SM, Lee SM, Kotaka M, Lee CY, Waye MM, Fung KP (2002) Interaction of the heart-specific LIM domain protein, FHL2, with DNA-binding nuclear protein, hNP220. J Cell Biochem 84: 556-566.

Rafael MS, Laizé V, Florindo C, Ferraresso S, Bargelloni L, Cancela ML (2012) Overexpression of four and a half LIM domains protein 2 promotes epithelial-mesenchymal transition-like phenotype in fish pre-osteoblasts. Biochimie 94: 1128-1134.

Resnick KE, Frankel WL, Morrison CD, Fowler JM, Copeland LJ, Stephens J, Kim KH, Cohn DE (2010) Mismatch repair status and outcomes after adjuvant therapy in patients with surgically staged endometrial cancer. Gynecol Oncol 117: 234-238.

Rétaux S, Bachy I (2002) A short history of LIM domains (1993-2002): From protein interaction to degradation. Mol Neurobiol 26: 269-281.

Samson T, Smyth N, Janetzky S, Wendler O, Müller JM, Schüle R, von der Mark H, von der Mark K, Wixler V (2004) The LIM-only proteins FHL2 and FHL3 interact with alpha- and beta-subunits of the muscle alpha7beta1 integrin receptor. J Biol Chem 279: 28641-28652.

Scholl FA, McLoughlin P, Ehler E, de Giovanni C, Schäfer BW (2000) DRAL is a p53-responsive gene whose four and a half LIM domain protein product induces apoptosis. J Cell Biol 151: 495-506.

Schultze A, Fiedler W (2011) Clinical importance and potential use of small molecule inhibitors of focal adhesion kinase. Anticancer Agents Med Chem 11: 593-599.

Siegel R, Naishadham D, Jemal A (2012) Cancer statistics, 2012. CA Cancer J Clin 62: 10-29.

Turley EA, Veiseh M, Radisky DC, Bissell MJ (2008) Mechanisms of disease: epithelial-mesenchymal transition - does cellular plasticity fuel neoplastic progression? Nat Clin Pract Oncol 5: 280-290.

Vermeulen SJ, Bruyneel EA, Bracke ME, De Bruyne GK, Vennekens KM, Vleminckx KL, Berx GJ, van Roy FM, Mareel MM (1995) Transition from the noninvasive to the invasive phenotype and loss of $\alpha$-catenin in human colon cancer cells. Cancer Res 55: 4722-4728.

Wang J, Yang Y, Xia HH, Gu Q, Lin MC, Jiang B, Peng Y, Li G, An X, Zhang Y, Zhuang Z, Zhang Z, Kung HF, Wong BC (2007) Suppression of FHL2 expression induces cell differentiation and inhibits gastric and colon carcinogenesis. Gastroenterology 132: 1066-1076.

Wang SF, Oh S, Si YX, Wang ZJ, Han HY, Lee J, Qian GY (2012) Computational prediction of protein-protein interactions of human tyrosinase. Enzyme Res 2012: 192867.

Wei Y, Renard CA, Labalette C, Wu Y, Lévy L, Neuveut C, Prieur X, Flajolet M, Prigent S, Buendia MA (2003) Identification of the LIM protein FHL2 as a coactivator of $\beta$-catenin. J Biol Chem 278: 5188-5194.

Xia T, Lévy L, Levillayer F, Jia B, Li G, Neuveut C, Buendia MA, Lan K, Wei Y (2013) The four and a half LIM-only protein 2 (FHL2) activates transforming growth factor $\beta$ (TGF- $\beta$ ) signaling by regulating ubiquitination of the E3 ligase Arkadia. J Biol Chem 18: 1785-1794.

Yan JH, Ye QN, Fang Y, Zhu JH, Huang CF (2003) Mapping of FHL2 transcription activation domain. Acta Biochim Biophys Sin 35: 643-648.

Zhang W, Jiang B, Guo Z, Sardet C, Zou B, Lam CS, Li J, He M, Lan HY, Pang R, Hung IF, Tan VP, Wang J, Wong BC (2010) Four-and-a-half LIM protein 2 promotes invasive potential and epithelial-mesenchymal transition in colon cancer. Carcinogenesis 31: 1220-1229.

Zhang W, Wang J, Zou B, Sardet C, Li J, Lam CS, Ng L, Pang R, Hung IF, Tan VP, Jiang B, Wong BC (2011) Four and a half LIM protein 2 (FHL2) negatively regulates the transcription of E-cadherin through interaction with Snaill. Eur J Cancer 47: 121-130.

This work is published under the standard license to publish agreement. After 12 months the work will become freely available and the license terms will switch to a Creative Commons AttributionNonCommercial-Share Alike 3.0 Unported License.

Supplementary Information accompanies this paper on British Journal of Cancer website (http://www.nature.com/bjc) 